\title{
Orphan drug policies and use in pediatric nephrology
}

\author{
$\operatorname{Diana}_{\operatorname{Karpman}^{1}}{ }^{(\mathbb{D})} \cdot$ Peter Höglund ${ }^{2}$
}

Received: 13 September 2016 / Accepted: 15 September 2016/Published online: 13 October 2016

(C) IPNA 2016

\begin{abstract}
Orphan drugs designed to treat rare diseases are often overpriced per patient. Novel treatments are sometimes even more expensive for patients with ultra-rare diseases, in part due to the limited number of patients. Pharmaceutical companies that develop a patented life-saving drug are in a position to charge a very high price, which, at best, may enable these companies to further develop drugs for use in rare disease. However, is there a limit to how much a life-saving drug should cost annually per patient? Government interventions and regulations may opt to withhold a life-saving drug solely due to its high price and cost-effectiveness. Processes related to drug pricing, reimbursement, and thereby availability, vary between countries, thus having implications on patient care. These processes are discussed, with specific focus on three drugs used in pediatric nephrology: agalsidase beta (for Fabry disease), eculizumab (for atypical hemolytic uremic syndrome), and cysteamine bitartrate (for cystinosis). Access to and costs of orphan drugs have most profound implications for patients, but also for their physicians, hospitals, insurance policies, and society at large, particularly from financial and ethical standpoints.
\end{abstract}

Keywords Orphan drug · Rare disease · Quality-adjusted life-year $\cdot$ Fabry disease $\cdot$ Atypical hemolytic uremic syndrome $\cdot$ Cystinosis

Diana Karpman

diana.karpman@med.lu.se

1 Department of Pediatrics, Clinical Sciences Lund, Lund University, 22185 Lund, Sweden

2 Department of Clinical Chemistry and Pharmacology, Laboratory Medicine Lund, Lund University, Lund, Sweden

\section{Introduction}

Rare diseases are severe, chronic, debilitating, and/or lifethreatening conditions that are often hereditary and, by definition, affect less than 1 in 2000 individuals in the European Union (http://ec.europa.eu/health/human-use/orphanmedicines), or fewer than 200,000 individuals in the USA, at any given time (http://rarediseases.org). There is an estimate of close to 7000 rare diseases altogether [1,2], and the cumulative prevalence is estimated to affect up to $6-8 \%$ of the world's population [3]. Ultra-rare diseases have a prevalence of 1 in 50,000 individuals or less in Europe (EU regulation 536/2014). Most ultra-rare diseases have a much lower prevalence, affecting as few as $0.5-1$ per million inhabitants. Biotechnology research and development of specific treatments for rare diseases by pharmaceutical companies is a very expensive process, and the cost of treatment per patient is very high due to the low prevalence of each condition. Orphan drug legislation has provided incentives and facilitated the development of these products, but the cost, and societal restrictions on reimbursement, may impede their use and thus patient benefit. Health economic equations utilized to analyze costeffectiveness may not be generally applicable, and especially so to ultra-rare diseases, but nevertheless affect reimbursement policies and patient health. We will describe these processes and their impact on patients and society, giving examples relevant to pediatric nephrology. The ethical aspects of providing or withholding very expensive, albeit effective, drugs will be discussed.

\section{The patient's perspective}

The patient with a rare or ultra-rare disease may require treatment with a very expensive drug. The patient may experience 
variable outcomes depending on the specific disease phenotype, drug availability, government policies, society regulations, and geographical location. Doctors have an ethical obligation to treat their patients with the best available drug. Withholding a drug due to its cost is contradictory to an acceptable patient-doctor relationship, but access to an expensive drug may be limited by regulations or policies, whether societal or imposed by private insurance companies. Societal costs for individuals with a rare disease will be low due to the exclusivity of the specific condition, but the costs will add up when treatment of many rare diseases are accounted for, as an estimate of over 55 million patients are affected by rare diseases in the USA and Europe [4] (http://ec.europa. eu/health/rare_diseases/expert_group/index_en.htm). The cost of one specific drug with indisputable effect may be very high, but may be equivalent to or less than the total costs for multiple less expensive treatments in patients with a debilitating trauma or handicap [5]. The latter costs are indisputable; the accumulative price tag for patients treated in intensive care units for multi-trauma or for children born with handicaps is not an ethically acceptable discussion issue. In contrast, the price tag for an effective, albeit expensive, drug for saving the life of a patient with a rare disease is disputable. Patient organizations are therefore imperative to assemble patients with specific rare diseases and represent them as a group [6]. In addition to offering support and information to patients and their parents, and contributing to research efforts and national plans for patient care [7], these advocacy groups promote public awareness of a rare disease and lobby for therapy availability with the appropriate authorities. The independence of patient organizations is therefore essential to avoid excessive industrial influence [7].

National organizations representing rare diseases as a whole, such as NORD in the USA (National Organization of Rare Disorders) and EURORDIS in Europe, can petition authorities on behalf of patients. The European Reference Networks (ERNs) for rare diseases identify centers of expertise and also advise patients and their organizations where to turn to (http://ec.europa.eu/health/rare_diseases/policy/index en.htm).

\section{The pharmaceutical companies' investments}

The development of a drug for a rare disease is preceded by academic research into the disease pathogenesis followed by investigation of the pharmacological properties of the drug, its toxicity, and phase I-III trials. The patent period is 20 years, of those up to 12 years are often required for research and development until drug registration and marketing [8]. Pharmaceutical companies developing medicines for use in rare diseases take a big risk requiring large capital investments (sums between $\$ 500$ million and $\$ 2$ billion have been reported
[9]) for drugs that may not prove to be effective, or even if they are, may take many years to assess in conditions with very low prevalence. These medicines are designated "orphan drugs" during development and receive financial benefits before approval (described below) in order to promote incentive [10]. Once the medicine obtains market approval, these companies enjoy a patented monopoly for several years and thus a lack of competition [11]. Hence, they expect returns for the cost of development and production, in addition to large revenues, which may not be entirely justified, but exploited due to their exclusive rights [5]. Orphan drug affordability becomes a financial strain that affects the long-term trust of the health-care system, and society at large, on the pharmaceutical industry involved in the development of these drugs [12].

\section{Orphan drug legislation}

Orphan drug legislation was introduced in the USA in 1983 (The Orphan Drug Act) and in the EU in 2000 (EU regulation (CE) $\left.\mathrm{N}^{\circ} 141 / 2000\right)$ to facilitate the development of orphan drugs. Product development is initiated when an application for orphan drug designation is approved, allowing the company to proceed with certain benefits and fiscal incentives, including reduction of regulatory fees, tax credit for the costs of studies, fee waivers, priority review for authorization, and 7 (USA) or 10 (Europe) years of market exclusivity per indication [3, 13, 14]. A recent comprehensive review showed that most European, Asian, and North American countries (27/35) had adopted orphan drug legislation [3] and that these regulations have promoted the development of orphan products [15-17] although some issues, pertaining to pricing, have arisen, regarding incentives given to companies that later reap huge profits [18].

\section{Cost-effectiveness of an orphan drug}

Once a drug is market-authorized and available, even if highly effective, its accessibility may be limited by its price [19]. If the price is excessively high, availability will depend on coverage and reimbursement policies and regulations, imposed by society as well as by insurance companies. Health technology assessment (HTA), the systematic appraisal of a novel therapy and its consequences, is usually applied [3]. Governmental agencies may rely on incremental cost-effectiveness ratios (ICERs) for evaluation of drug price in relation to health benefits. ICERs that exceed a given threshold will not be covered and reimbursed. Patient co-payment strategies and hospital reimbursements may thereby also be dictated by these equations. One of the most utilized equations is QALY (qualityadjusted life-years), which takes into account both morbidity (quality of life) and mortality (life expectancy), in which 1 year 
of healthy life is equivalent to " 1 " and death is equivalent to " 0 ". The novel intervention, to be assessed, is compared to a standard treatment. A limit is set regarding how much society is willing to pay for an increment of 1 QALY (approximately $£ 30,000$ in the UK or $\$ 100,000-150,000$ in the USA [20]), with a somewhat higher threshold for ultra-rare diseases.

QALY ratios utilized for assessment of orphan drugs may have certain shortcomings [3,5]. In the calculation of QALYs, an inherent assumption is that the quality of life scale (Y-axis) and the time scale (X-axis) are linear, which is seldom the case in clinical practice. Furthermore, evaluation of health gains in ultra-rare disease may be difficult to assess due to the very low prevalence of cases in each disease category. Alternative treatments for comparison may not be available. Also, the perception of health differs between the patient and the observer, and an orphan drug may improve health immensely, whereas the QALY increment would be the same as a painkiller against chronic headaches. In addition, the improvement of family life is not accounted for (for example, lost work days for relatives) and health benefits do not take into account societal benefits, the ability to function in society, and long-term tax revenues from being able to work throughout a lifetime.

Recently the European Consortium in Healthcare Outcomes and Cost-Benefit Research (echoutcom.eu) recommended that QALY assessment for healthcare decision making should be abandoned. Instead, they recommended that cost-effectiveness analyses should be expressed as cost per relevant clinical outcome, such as, for example, dialysis-free survival. Certain orphan drugs are only efficient in a subgroup of patients with a rare disease [5] and thus drugs should be appraised based on their overall therapeutic benefit for patients with a specific disease.

\section{Regulations imposed by society}

The price of an orphan drug and reimbursement strategies are under the jurisdiction of each sovereign country, leading to decisions that may affect the national or regional budget, particularly if the drug is excessively costly. Regulations and policies regarding the use of a novel drug are typically imposed based on the above-mentioned ICERs, usually with a higher threshold for orphan drugs (increased willingness to reimburse) and a degree of leniency if the treatment is lifesaving $[1,3]$. Certain countries also have legislation regarding off-label use of orphan drugs as well as procedures for compassionate use [1]. A few countries disregard costeffectiveness ratios, to a certain extent, in favor of moral aspects, the so-called "rule of rescue", whereby saving a human life is valued more than the price of the intervention [3].

Studies have compared health policies regarding orphan drugs in various countries and on different continents $[1,3,19]$. These policies take into account incentives to promote the development of orphan drugs, market authorization, pricing and price regulation, budget impact, profit control, and reimbursement coverage, and show considerable variation between countries. Thus, inhabitants of different countries, and possibly even different regions within one country, may have variable access to treatment. Countries with advisory boards that rely almost exclusively on cost-effectiveness as a criterion for reimbursement generally exhibit less willingness to cover an excessive expense, and may thus recommend withholding treatment, in comparison to countries in which advisory boards primarily utilize evidence from case and cohort studies [3]. In addition to national reimbursement programs, certain countries have adopted co-payment strategies in which the pharmaceutical company, the patient, or private insurance companies, cover drug costs above a certain threshold [5]. This approach may, however, limit patient access or promote noncompliance [5, 19].

Registry data regarding the treatment of rare diseases are imperative in order to facilitate policy-making, particularly when taking into account cost-effectiveness ratios of orphan drugs. Registries collect data from larger groups of patients, globally or nationally, and should ideally function independently of the pharmaceutical industry $[1,2]$.

\section{Orphan drugs in pediatric nephrology}

Certain drugs used in pediatric nephrology are examples of the most expensive orphan drugs for the treatment of ultra-rare diseases. We will focus on three drugs: agalsidase beta (Fabrazyme, Genzyme) for the treatment of Fabry disease, eculizumab (Soliris, Alexion) for the treatment of atypical hemolytic uremic syndrome, and a slow-release formula of cysteamine bitartrate (Procysbi, Raptor) for the treatment of nephropathic cystinosis, and give examples of differences in reimbursement policies.

\section{Treatment of Fabry disease}

Fabry disease is a potentially lethal X-linked genetic disorder due to deficiency of the lysosomal enzyme alpha-galactosidase A, required for degradation of globotriaosylceramide. As a result, glycosphingolipids accumulate in many organs already during childhood, progressing throughout life. Patients may develop gastrointestinal symptoms, ophthalmological symptoms, renal failure, cardiomyopathy, neuropathic pain, strokes, angiokeratomas, and hypohidrosis [19, 21]. Agalsidase alpha and agalsidase beta were developed as enzyme replacement therapies providing alpha-galactosidase A [15]. Although not all Fabry patients require treatment, in 2013 a US consensus panel recommended the use of enzyme 
replacement therapies in pediatric Fabry patients who developed symptoms from major organs [21].

The cost of Fabrazyme (agalsidase beta) per year per adult patient was estimated at $\$ 200,000$. Reimbursement policies in various countries have been reported [19, 22]. These were based on cost-effectiveness, rule of rescue, and equity, showing that an unfavorable recommendation was given in Canada based on insufficient evidence for costeffectiveness, although each province could formulate their own decision, thus affecting drug access depending on where in the country the patient lived. A favorable recommendation was made in Israel, France, Slovakia, and Hungary and in Australia funding was recommended through the Life Saving Drug Program for which there are no co-payments [19, 22].

\section{Treatment of atypical hemolytic uremic syndrome}

Atypical hemolytic uremic syndrome (aHUS) manifests as recurrent episodes of hemolytic anemia, thrombocytopenia, and acute renal failure, and is often associated with heterozygous mutations in one or more complement proteins, or autoantibodies to the soluble complement regulator factor $\mathrm{H}$ [23]. The result is a hyperactive alternative pathway of complement leading to damage to host cells. Patients may develop end-stage renal failure either during the first episode or after several recurrences and the disease may recur after renal transplantation. Patients were previously exclusively treated with plasma exchange or infusions but the prognosis regarding renal function and mortality was poor until the introduction of eculizumab, which was shown to be highly effective in both adults and children with aHUS [24, 25]. Current international consensus (2015) recommends the start of eculizumab treatment upon diagnosis of aHUS, although treatment can be discontinued in a small subset of patients, particularly those with autoantibodies [23]. For all other patients, continuous treatment is recommended as long as the patient has renal function (native or transplant).

The annual cost of Soliris (eculizumab) treatment for an adult is approximately $\$ 400,000$ and topped the revenue per patient in the USA in 2014 [26]. After-market authorization reimbursement policies have varied considerably in different countries. The Food and Drug Administration (FDA) authorized its use for aHUS patients in the USA in 2011. Pricing of drugs in the USA is free. Reimbursement of orphan drugs is covered by commercial plans as well as state Medicaid plans and Medicare prescription drug plans, with certain out-ofpocket co-payments [27].

In the UK, the National Institute for Health and Care Excellence (NICE) recommended the use of eculizumab for aHUS due to substantial QALY gains, under strict monitoring conditions. In Scotland, the Scottish Medicines Consortium gave an unfavorable recommendation, i.e., to withhold eculizumab from aHUS patients. The reasoning given was that the pharmaceutical company did not present a sufficiently robust economic analysis. Irish Health Service Executive could also not assess cost-effectiveness but agreed to reimburse newly diagnosed patients. The Swedish committee for evaluation of novel therapies provided a rejection based on insufficient cost-effectiveness analysis, although this recommendation was given at a general level, allowing regional recommendations to vary. Thus, patients could be entitled, or not entitled, to treatment based on the region they live in and the locally available expertise.

\section{Treatment of nephropathic cystinosis}

Cystinosis is an ultra-rare lethal disease leading to end-stage renal failure and death when left untreated. The disease exhibits an autosomal recessive pattern of inheritance due to mutations in the CTNS gene, encoding cystinosin, leading to lysosomal cystine accumulation in cells [28]. Patients manifest with Fanconi syndrome, short stature, skeletal affection, and renal failure. Extra-renal manifestations, typically occurring in late childhood or adulthood, may include endocrinological complications, myopathy, and swallowing disturbances as well as cardiac and neurological symptoms [28]. The current recommended therapy is cystine depletion using cysteamine, which converts lysosomal cystine to cysteine, however, this treatment is not a cure and patients do not achieve full life expectancy [29]. International consensus recommends the initiation of cysteamine treatment upon diagnosis and continuation of treatment throughout life [29]. Cysteamine delays the onset of renal failure and extra-renal manifestations and improves life expectancy $[28,30]$.

Immediate-release cysteamine bitartrate [15] (Cystagon, Mylan Pharmaceuticals) is marketed as a treatment for cystinosis. This preparation requires administration every $6 \mathrm{~h}$ and has considerable gastrointestinal side effects [31]. A delayed-release preparation (Procysbi) given every $12 \mathrm{~h}$ within enteric-coated spheres reduced the side effects and improved quality of life, and thereby compliance to administration regimens [32]. Procysbi's annual price tag per patient is approximately $\$ 250,000$ compared to $\$ 10,000$ / year for Cystagon.

Similar to the situation described above for Fabrazyme and Soliris, Procysbi has also been approved by the FDA but as yet not recommended by advisory committees in other countries (for example The Swedish Council for Novel Therapies). The latter decision was made pending cost-effectiveness data. Recommendations for other countries are, as yet, unavailable. 


\section{The ethical issues}

Society has an obligation to provide healthcare to all on a fairallocation basis. The provision of hyper-expensive orphan drugs in the setting of health resource scarcity may erode public trust in the system. Can society afford the expense of exorbitantly expensive orphan drugs? Treatment of rare diseases, regardless how costly, would hardly affect the overall societal budget given the limited number of patients within each disease category, but, when all rare diseases are accounted for, the combined expense could put a huge strain on economic health-care resources.

How can society withhold care from a patient with a rare disease while providing care to the patient with a common disease or, vice versa, treat the one patient with a rare disease instead of many patients with a common disease? Would this constitute a form of discrimination based on diagnosis? Treatment of the one patient with a rare disease may be financially equivalent to treatment of multiple patients with a common disease [5] and raises issues of solidarity in health-care.

Relying heavily on cost-effectiveness ratios as parameters for guiding recommendations of treatment would seem immoral. Therefore, principles of equity and solidarity are also taken into account, as well as the severity of the disease and the degree of benefit achieved by the proposed orphan drug. In contrast, utilizing the "rule of rescue" as a sole parameter for approval of orphan drugs could also be discriminatory against those who are not in a life-threatening situation [5].

Alternatively, it has been proposed that costs could be allocated per patient and not per treatment [5]. Thus, the healthcare budget per patient would not take the number of treatments into account, whether one single drug or multiple treatments, the latter corresponding to the intensive care setting, or cancer therapy, but rather the total costs per patient.

Annual orphan drug sales have increased yearly. In the EvaluatePharma report on orphan drugs from 2015, orphan drug sales were forecast to total $\$ 178$ billion, up by $12 \%$ between 2015 and 2020. Orphan drugs sales would account for $20 \%$ of global prescription sales by 2020 (excluding generics) [26]. Doctors are trained to treat their patients, and withholding an available and effective drug, due to its price, or for any other reason, is against the professional code. Thus it has been suggested that the price of orphan drugs should be negotiated, for the patients' sake [2].

\section{Conclusions}

Patients with rare diseases should be entitled to appropriate treatment regardless of diagnosis. If appropriate treatment is withheld, patients will suffer, develop organ failure, and die, even though therapy is available, a consequence that would be morally unacceptable. The process of orphan drug research and development is risky and expensive, while the profits reaped by the pharmaceutical industry are exorbitant. Limited societal resources for collective orphan drug prescriptions will require improved price control. National advisory committees and pharmaceutical companies should work together to achieve the ultimate goal of better treatment regardless of diagnosis.

Acknowledgments The authors wish to acknowledge informative discussions with Dr. Karin Franck-Larsson, Director Medical Affairs Nordics, Raptor Pharmaceuticals Europe B.V.

\section{Compliance with ethical standards}

Disclosures The authors have no conflicts of interest to disclose.

Funding Diana Karpman is supported by grants from The Swedish Research Council (K2013-64X-14008-13-5 and K2015-99X-22877-016), The Knut and Alice Wallenberg Foundation (Wallenberg Clinical Scholar 2015.0320), The Torsten Söderberg Foundation, Skåne Centre of Excellence in Health, Crown Princess Lovisa's Society for Child Care, Region Skåne and Stiftelse Konung Gustaf V:s 80-årsfond. Peter Höglund is supported by grants from The Swedish Heart and Lung Foundation, Region Skåne and Fru Berta Kamprads stiftelse.

\section{References}

1. Denis A, Mergaert L, Fostier C, Cleemput I, Simoens S (2010) A comparative study of European rare disease and orphan drug markets. Health Policy 97:173-179

2. Luzzatto L, Hollak CE, Cox TM, Schieppati A, Licht C, Kaariainen H, Merlini G, Schaefer F, Simoens S, Pani L, Garattini S, Remuzzi $\mathrm{G}$ (2015) Rare diseases and effective treatments: are we delivering? Lancet 385:750-752

3. Gammie T, Lu CY, Babar ZU (2015) Access to orphan drugs: a comprehensive review of legislations, regulations and policies in 35 countries. PLoS One 10:e140002

4. Schieppati A, Henter JI, Daina E, Aperia A (2008) Why rare diseases are an important medical and social issue. Lancet 371:20392041

5. Hunter D, Wilson J (2011) Hyper-expensive treatments. Nuffield Council on Bioethics Forward Look 1-23

6. Ayme S, Kole A, Groft S (2008) Empowerment of patients: lessons from the rare diseases community. Lancet 371:2048-2051

7. Hollak CE, Biegstraaten M, Baumgartner MR, Belmatoug N, Bembi B, Bosch A, Brouwers M, Dekker H, Dobbelaere D, Engelen M, Groenendijk MC, Lachmann R, Langendonk JG, Langeveld M, Linthorst G, Morava E, Poll-The BT, Rahman S, Rubio-Gozalbo ME, Spiekerkoetter U, Treacy E, Wanders R, Zschocke J, Hagendijk R (2016) Position statement on the role of healthcare professionals, patient organizations and industry in European reference networks. Orphanet J Rare Dis 11:7

8. Moors EHM, Faber J (2007) Orphan drugs: unmet societal need for non-profitable privately supplied new products. Res Policy 36:336354

9. Adams CP, Brantner VV (2006) Estimating the cost of new drug development: is it really 802 million dollars? Health Aff (Millwood) 25:420-428 
10. Ferner RE, Hughes DA (2010) The problem of orphan drugs. BMJ 341:c6456

11. Godlee F (2010) Stop exploiting orphan drugs. BMJ 341:c6587

12. O'Sullivan BP, Orenstein DM, Milla CE (2013) Pricing for orphan drugs: will the market bear what society cannot? JAMA 310:13431344

13. Haffner ME, Torrent-Farnell J, Maher PD (2008) Does orphan drug legislation really answer the needs of patients? Lancet 371:20412044

14. Heemstra HE, van Weely S, Buller HA, Leufkens HG, de Vrueh RL (2009) Translation of rare disease research into orphan drug development: disease matters. Drug Discov Today 14:1166-1173

15. Talele SS, Xu K, Pariser AR, Braun MM, Farag-El-Massah S, Phillips MI, Thompson BH, Cote TR (2010) Therapies for inborn errors of metabolism: what has the orphan drug act delivered? Pediatrics 126:101-106

16. Thorat C, Xu K, Freeman SN, Bonnel RA, Joseph F, Phillips MI, Imoisili MA (2012) What the orphan drug act has done lately for children with rare diseases: a 10-year analysis. Pediatrics 129:516521

17. Rzakhanov Z (2008) Regulatory policy, value of knowledge assets and innovation strategy: the case of the orphan drug act. Res Policy 37:673-689

18. Wellman-Labadie O, Zhou Y (2010) The US orphan drug act: rare disease research stimulator or commercial opportunity? Health Policy 95:216-228

19. Blankart CR, Stargardt T, Schreyogg J (2011) Availability of and access to orphan drugs: an international comparison of pharmaceutical treatments for pulmonary arterial hypertension, Fabry disease, hereditary angioedema and chronic myeloid leukaemia. Pharmacoeconomics 29:63-82

20. Shiroiwa T, Sung YK, Fukuda T, Lang HC, Bae SC, Tsutani K (2010) International survey on willingness-to-pay (WTP) for one additional QALY gained: what is the threshold of cost effectiveness? Health Econ 19:422-437

21. Hopkin RJ, Jefferies JL, Laney DA, Lawson VH, Mauer M, Taylor MR, Wilcox WR, Fabry Pediatric Expert P (2016) The management and treatment of children with Fabry disease: a United Statesbased perspective. Mol Genet Metab 117:104-113

22. Rosenberg-Yunger ZR, Daar AS, Thorsteinsdottir H, Martin DK (2011) Priority setting for orphan drugs: an international comparison. Health Policy 100:25-34

23. Loirat C, Fakhouri F, Ariceta G, Besbas N, Bitzan M, Bjerre A, Coppo R, Emma F, Johnson S, Karpman D, Landau D, Langman CB, Lapeyraque AL, Licht C, Nester C, Pecoraro C, Riedl M, van de Kar NC, Van de Walle J, Vivarelli M, Fremeaux-Bacchi V, International HUS (2016) An international consensus approach to the management of atypical hemolytic uremic syndrome in children. Pediatr Nephrol 31:15-39

24. Legendre CM, Licht C, Muus P, Greenbaum LA, Babu S, Bedrosian C, Bingham C, Cohen DJ, Delmas Y, Douglas K, Eitner F, Feldkamp T, Fouque D, Furman RR, Gaber O, Herthelius M, Hourmant M, Karpman D, Lebranchu Y, Mariat C, Menne J, Moulin B, Nurnberger J, Ogawa M, Remuzzi G, Richard T, Sberro-Soussan R, Severino B, Sheerin NS, Trivelli A, Zimmerhackl LB, Goodship T, Loirat C (2013) Terminal complement inhibitor eculizumab in atypical hemolytic-uremic syndrome. N Engl J Med 368:2169-2181

25. Greenbaum LA, Fila M, Ardissino G, Al-Akash SI, Evans J, Henning P, Lieberman KV, Maringhini S, Pape L, Rees L, van de Kar NC, Vande Walle J, Ogawa M, Bedrosian CL, Licht C (2016) Eculizumab is a safe and effective treatment in pediatric patients with atypical hemolytic uremic syndrome. Kidney Int 89:701-711

26. EvaluatePharma Orphan Drug 2015 3rd ed, Evaluate, London UK

27. Hyde R, Dobrovolny D (2010) Orphan drug pricing and payer management in the United States: are we approaching the tipping point? Am Health Drug Benefits 3:15-23

28. Gahl WA, Balog JZ, Kleta R (2007) Nephropathic cystinosis in adults: natural history and effects of oral cysteamine therapy. Ann Intern Med 147:242-250

29. Langman CB, Barshop BA, Deschenes G, Emma F, Goodyer P, Lipkin G, Midgley JP, Ottolenghi C, Servais A, Soliman NA, Thoene JG, Levtchenko EN, Conference P (2016) Controversies and research agenda in nephropathic cystinosis: conclusions from a "kidney disease: improving global outcomes" (KDIGO) controversies conference. Kidney Int 89:1192-1203

30. Brodin-Sartorius A, Tete MJ, Niaudet P, Antignac C, Guest G, Ottolenghi C, Charbit M, Moyse D, Legendre C, Lesavre P, Cochat P, Servais A (2012) Cysteamine therapy delays the progression of nephropathic cystinosis in late adolescents and adults. Kidney Int 81:179-189

31. Langman CB, Greenbaum LA, Sarwal M, Grimm P, Niaudet $P$, Deschenes G, Cornelissen E, Morin D, Cochat P, Matossian D, Gaillard S, Bagger MJ, Rioux P (2012) A randomized controlled crossover trial with delayed-release cysteamine bitartrate in nephropathic cystinosis: effectiveness on white blood cell cystine levels and comparison of safety. Clin J Am Soc Nephrol 7:1112-1120

32. Langman CB, Greenbaum LA, Grimm P, Sarwal M, Niaudet P, Deschenes G, Cornelissen EA, Morin D, Cochat P, Elenberg E, Hanna C, Gaillard S, Bagger MJ, Rioux P (2014) Quality of life is improved and kidney function preserved in patients with nephropathic cystinosis treated for 2 years with delayed-release cysteamine bitartrate. J Pediatr 165(528-533):e521 